\title{
Conserving Rajaji and Corbett National Parks - the elephant as a flagship species
}

\author{
A. J. T. Johnsingh and Justus Joshua
}

One of India's five major populations of elephants lives in north-west India, where 90 per cent of the total 750 elephants occur in Rajaji and Corbett National Parks. and adjacent reserve forests. This 3000-sq-km habitat is also home to many other endangered species. While the $520-\mathrm{sq}-\mathrm{km}$ core area of Corbett National Park is free from human impact, the rest of the range is subject to increasing pressures, both from the pastoral Gujjar community within the forests and villagers outside. The elephant habitat has been fragmented by hydrological development work and human-elephant conflict is increasing. The authors recommend measures that need to be implemented to ensure that the elephants and other wildlife of the area are conserved.

\section{Introduction}

Over the last two decades many habitat conservation programmes have adopted particular species to serve as 'flagship species'. By focusing on one species and its conservation needs, large areas of habitat can be managed, not only for the species in question but for a whole range of less charismatic taxa. In India, the tiger Panthera tigris was used as a flagship species when 'Project Tiger' was started in 1973. Despite the enormous odds, the project has improved the chances of the tiger's survival, saved large areas of habitat and maintained biological diversity (Panwar, 1987).

Since the inception of 'Project Tiger' India's human population rose from about 550 million to 840 million in 1990 and with it the associated demands for natural resources from wilderness areas. As a result of growing political unrest, deforestation and poaching, the achievements of Project Tiger and allied conservation projects are being eroded. There is an urgent need to identify another species of comparable glamour and ecological suitability to inject vigour into conservation programmes and to win public support in India. 'Project Elephant', in which elephant reserves or conservation units covering much larger areas than those designated as tiger reserves and which would be managed under a special scheme (Johnsingh and Panwar, 1992), would be a step towards action on this.

The Asian elephant Elephas maximus conforms to the role of a flagship species extremely well. To maintain viable populations, many large areas will be needed in its range, each containing more than 500 breeding adults (Santiapillai and Jackson, 1990), as well as plentiful clean water, abundant forage and protection from poaching. By pushing down trees and creating trails in dense scrub and tall grassland, elephants facilitate the feeding and movement of many other grazing and browsing mammals. A well-managed elephant conservation unit will be an excellent habitat for numerous other species. Above all, the elephant is an integral part of Indian culture and religion and therefore it should be possible to gain public support for its protection.

In this paper we outline the conservation strategies needed to manage the Rajaji and Corbett National Parks in Uttar Pradesh as one elephant conservation unit.

\section{Elephant habitat}

Uttar Pradesh has one of five populations of elephants in India (Daniel, 1980). The 


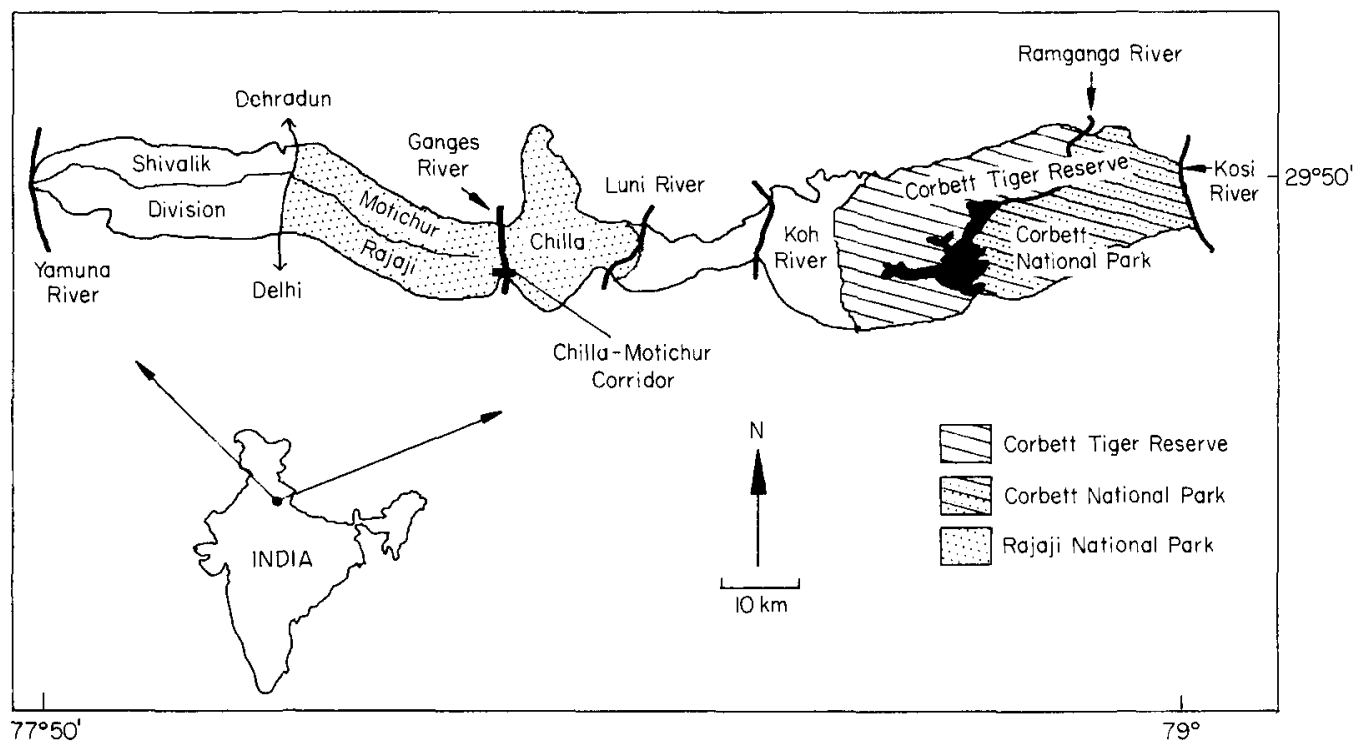

Figure 1. Rajaji-Corbett elephant range.

suggested Rajaji-Corbett Elephant Reserve includes the present Shivalik forest division, Rajaji National Park (820 sq km); Corbett Tiger Reserve (1320 sq km, of which $520 \mathrm{sq} \mathrm{km}$ is a core area and a national park), and parts of four other forest divisions $\left(29^{\circ} 25^{\prime}\right.$ to $30^{\circ} 13^{\prime} \mathrm{N}$ and $77^{\circ} 54^{\prime}$ to $79^{\circ} 05^{\prime} \mathrm{E}$ ). East to west, this area stretches between the Kosi River, which forms the eastern boundary of Corbett Tiger Reserve, and the Yamuna River at the western end of Shivalik forest division (Figure 1). This would cover about $3000 \mathrm{sq} \mathrm{km}$ of elephant range with an estimated 650 elephants, 90 per cent of the total number in Uttar Pradesh (Singh, 1986). The range is fragmented into three units: west of the Ganges; between the Ganges and Koh rivers; and between the Koh and Kosi rivers (Figure 1). Genetic continuity between fragmented populations is maintained, however, by the migration of bulls.

North to south this elephant range is divisible broadly into the outer Himalaya and the Shivalik hills. The latter form nearly 70 per cent of the elephant habitat. The altitude in this range varies between 300 and $1000 \mathrm{~m}$. Locally, the Shivaliks and the foothills of the Himalaya are called the 'bhabar' tract. The ad- jacent 'terai' belt, with dense tall grass, a high water table and a once abundant large mammal fauna (for example, elephant and greater Indian one-horned rhinoceros Rhinoceros unicornis), has been lost to agriculture, human settlements and plantations.

The vegetation of the bhabar tract is dry deciduous woodland dominated by Shorea robusta, Anogeissus latifolia, Mallotus philippinensis and Acacia catechu. Bamboo Dendrocalamus strictus was once abundant throughout this tract. The understorey in many places is dominated by alien and indigenous weeds. Grassland is restricted to riverine areas and hill slopes.

\section{Other key vertebrate fauna}

Other wildlife in the range include 100-150 tigers and over 300 leopards Panthera pardus. Large ungulate prey are sambar Cervus unicolor, nilgai Boselaphus tragocamelus, chital Cerous axis, hog deer Cerous porcinus, Indian muntjac Muntiacus muntjak, wild pig Sus scrofa and goral Nemorhaedus goral. The golden jackal Canis aureus is common and the Himalayan 
yellow-throated marten Martes flavigula is seen occasionally. Dhole Cuon alpinus, wolf Canis lupus and hyaena Hyaena hyaena are rare, while primates are represented by rhesus macaque Macaca mulatta and Hanuman langur Presbytis entellus.

Birds of conservation concern are the hornbills Tockus birostris, Anthracoceros malabaricus and Buceros bicornis, yellow-legged green pigeon Treron phoenicoptera, kalij pheasant Lophura leucomelana and red junglefowl Gallus gallus. Three species of endangered reptiles occur: the king cobra Ophiophagus hannah, which occurs throughout the area, the gharial Gavialis gangeticus and the mugger Crocodylus palustris, both confined to the Ramganga River and the reservoir in Corbett. These water bodies are the last stronghold for the endangered golden mahseer Tor putitora, a fish highly valued by anglers.

\section{The problems}

The major problems threatening the conservation of elephants and other wildlife in this area are the lingering effects of the loss of habitat through the development projects of the early 1970s, and increasing pressures wood-cutting, tree-lopping, grass-cutting, cattle grazing - from the pastoral Gujjars who live inside the forest and from villagers from outside. As a result of these pressures, weeds proliferate, forage species do not regenerate and water bodies are polluted by people and livestock. Poaching is a menace and conflict between humans and elephants seems to be increasing.

\section{Loss of habitat}

The decrease in the extent of wildlife habitat is largely because of the increase in human population and the resultant demand for more land. For example, the human population around Rajaji National Park alone doubled between $1951(188,957)$ and $1981(409,773)$, resulting in the loss of $70 \mathrm{sq} \mathrm{km}$ of forest land to townships and development projects (Johnsingh, 1991). Although not quantified, similar habitat loss has occurred all along the southern boundary of the elephant range.

\section{Development projects}

Construction of the Ramganga reservoir and the Kunaun-Chilla power channel, both of which were completed in the early 1970s, have led to fragmentation of the elephant habitat. When the reservoir, which extends over $80 \mathrm{sq}$ $\mathrm{km}$ soon after the rains in July-September, filled in 1974, it severed the regular elephant migratory route between Corbett National Park and the western part of the Tiger Reserve. Although a few elephant groups eventually found a way across the hills north of the reservoir to the bamboo-rich western part of the reserve, the migratory patterns and habitat use of the elephants in Corbett remain affected (Singh, 1978) because the reservoir township prevents elephants from migrating along the southern boundary

The 14-km-long power channel runs parallel to the left bank of the Ganges and has drastically reduced elephant access from Chilla to the river. Nearly $15 \mathrm{sq} \mathrm{km}$ of habitat, which includes at least $8 \mathrm{sq} \mathrm{km}$ of grassland, has also become inaccessible to elephants because of the channel and encroachment (Singh, 1978). Similarly, development on the west bank of the Ganges has stopped elephant groups from Motichur using the Ganges, although bulls are able to move across the river and the power channel on a narrow bridge. Groups avoid moving through disturbed areas because of the danger to calves.

\section{Increasing biotic pressures}

Gujjar settlements are spread across the elephant range except in Corbett National Park. Their total number could be around 20,000 (c. 2000 families). They raise buffaloes for milk, and feed them by lopping trees. Repeated lopping affects tree reproduction and reduces their capacity to prevent erosion that could be caused by heavy rains, especially in the geologically young Shivaliks. Gujjars even lop fruit trees such as Bridelia retusa, Emblica officianalis, Ficus benghalensis, F. rumphi and 
Zizyphus mauritiana, which are crucial for frugivorous birds and mammals.

In the past the Gujjars used to leave the Shivaliks around April for high altitude pastures in the Himalaya, where they stayed until October. Now the resident graziers in the Himalaya, who find their meadows overcrowded, have begun to resent this migration. Most of the Gujjars, therefore, have stopped migrating and their demands on the habitat have increased.

A significant portion of the pressure is exerted by the villages on the periphery of the elephant habitat. A study of four villages on the border of the Rajaji-Corbett corridor showed that the villagers and their livestock obtain 6-37 per cent of their livestock's fodder needs and 95 per cent of their fuel-wood requirements from the forest ( $\mathrm{R}$. Badola and $\mathrm{B}$. $\mathrm{K}$. Mishra, unpubl. data). There is evidence from the last 6 years to suggest frequent and increasing poaching along the periphery of Rajaji National Park (pers. obs.), which could be true for other parts of the elephant range.

\section{Weed proliferation and lack of regeneration}

Weeds proliferate when there is overgrazing by livestock (Dabadghao and Shankarnarayan, 1973). In Rajaji National Park the non-food shrubs formed 57 per cent of the total shrub cover. On the banks of the Ganges in Rajaji National Park, an area subjected to intensive grazing, the five most abundant herb species were Cassia tora, Parthenium hysterophorus, Cannabis sativa, Pogostemon benghalensis and Sida rhombifolia: only the two latter species are native and none is eaten by ungulates. Although grass species, such as Chloris dolichostachya and Digitaria spp. were present, their contribution to the total herbaceous biomass was insignificant. Six preferred elephant food-tree species - Dalbergia sisso, Kydia calycina, Shorea robusta, Zizyphus xylopyrus, Bridelia retusa and Grewia tiliaefolia showed little or no regeneration. In the absence of regeneration most of the food tree species face local extinction. Johnsingh et al., (1990) made similar observations in the Chilla-Motichur corridor.
Pollution of water by livestock and people

A. Rajvanshi and A. J. T. Johnsingh (unpubl. data) noted the lack of clean water for elephants to drink in summer 1991. Water samples from nine different watering places were analysed for $\mathrm{pH}$, total dissolved solids, dissolved oxygen, chemical oxygen demand and biological pollution index. Only the spring waters were fit for human consumption and here we observed elephants drinking and also Gujjars collecting drinking water. The streams looked clean despite buffaloes wallowing, defecating and urinating in them and, while elephants crossed them, they did not drink from them. A large herd of elephants can take nearly an hour to drink at a spring and we observed impatient Gujjars waiting their turn: had it not been for our presence we suspect that they would have driven the elephants away by shouting and throwing stones. Competition for spring water between Gujjars and elephants could occur every summer throughout the elephant range except in Corbett National Park.

\section{Human--elephant conflict}

The factors that contribute to the killing of humans by elephants are the entry of people into elephant habitat to collect for firewood and fodder, conflict over water, and cultivation of palatable crops near the forest boundary. Between 1980 and 199070 people were killed by elephants in Rajaji-Corbett. Such incidents appear to be increasing, because 44 of these occurred between 1986 and 1990.

\section{Restoration of elephant habitat}

In Rajaji-Corbett human pressure may eventually eliminate all large species of wildlife. Restoring the habitat to satisfy the primary needs of the elephant as well as other wildlife would require total protection and habitat improvement through weed eradication and promoting the regeneration of palatable species. The task is enormous but several measures are recommended as priorities. 


\section{Strengthening the corridors}

Two corridors are crucial to maintain habitat continuity and ensure genetic exchange of the large mammals in this tract. These are the Chilla-Motichur and Rajaji-Corbett corridors. The most threatened, because of the accessible terrain, is the Chilla-Motichur corridor and it needs immediate attention. Johnsingh et al., (1990) made four recommendations for conservation action: (1) acquisition of land for the corridor; (2) banning cattle grazing and other human activities from the islands on the Ganges; (3) relocating Gangabhagpur village, which is between the Ganges and the channel on the east bank, instead of broadening the existing bridges and building new ones; and (4) enforcing protection of the corridor to allow vegetation to recover and facilitate large wild mammal use of the area. These need to be urgently implemented. Strengthening this corridor would also restore genetic continuity between tiger populations of the east and west banks of the Ganges.

W. Suderraj, B. K. Mishra and A. J. T. Johnsingh (unpubl. data) found that elephant herds were prevented from moving through Rajaji-Corbett corridor across the Koh River because of the steep terrain and human disturbance. Efforts should be initiated to reduce human disturbance to allow elephant bulls and other wildlife, particularly tiger, to continue to use the corridor.

\section{Settling Gujjars outside the elephant range}

Although quantified information is not available, our observations indicate that the current life-style of the increasing Gujjar population is not ecologically sustainable. Despite unrestricted lopping of trees, the Gujjars are not able to feed their buffaloes adequately. They complain of weed abundance and reduced milk production. In 1983 the Uttar Pradesh Forest Department embarked upon a scheme to settle the Gujjars outside the park. Despite investing Rs30million ( $\$ U S 1,200,000)$ in the resettlement package, the scheme has been unsuccessful, which suggests that the Gujjars need to be offered a deal that is more compati- ble with their needs. Khati (1990) has made many useful suggestions, including freeing the Gujjars from being dependent on middlemen, giving them more land, high- milk-yielding buffaloes and promoting stall feeding.

There are about $200 \mathrm{sq} \mathrm{km}$ of land planted with Eucalyptus in the terai (A. S. Negi, pers. comm.) and we suggest that each Gujjar family should be given at least 1 ha of this for housing, fodder and grain production. This land should be used for resettling Gujjars now or it will be used eventually for some other development work and the elephant range in Rajaji-Corbett will be degraded further by the increasing demands of the growing Gujjar population. Johnsingh (1991) questioned whether the Government would act urgently and carefully to resettle the Gujjars or delay the matter indefinitely through indecisive discussions until the wildlife values of the Shivaliks are irrevocably lost.

\section{Reducing pressures from outside}

Even if the Gujjars are resettled, pressures from outside would continue and would need to be minimized. Punitive policing of the protected areas can succeed only in the short term. Over much of the world, wilderness is invaded out of necessity. Only by removing the necessity can the wilderness be saved (Harcourt et al., 1986). Dobias (1991) suggested participatory management, fuel-wood plantations, small-scale wildlife tourism, conservation education, health care and family planning, which can generally enable the villagers to make the transition from exploiting the forest. To make these things work in India, committed officials are needed at all levels of state and national government as well as in nongovernment organizations.

\section{Management recommendations}

Rajaji-Corbett Elephant Reserve needs to be notified urgently under 'Project Elephant'. A wildlife-orientated officer in the rank of Chief Conservator of Forests, pledged to conservation, needs to be appointed as Director of the reserve. The conservation programme for 
the reserve should be three-pronged. One prong should promote schemes such as weed eradication, restoring habitat continuity and protection. Another should co-ordinate ecologically sustainable, income-generating programmes for villagers living near the reserve to reduce their dependency on the forest. The third should successfully resettle the Gujjars and look after their welfare. The government should be willing to have such a programme, involving the local non-governmental organizations in the management of the buffer zones of the reserve. If sustained, such a programme would improve the conservation status of the elephant, its habitat and other endangered species in this area and would also serve as a management model for areas with similar problems.

\section{Acknowledgments}

Mr H. S. Panwar, Director of the Institute, supported the elephant research in Rajaji-Corbett. Mr A. S. Negi, Field Director, Corbett National Park; Mr D. V. S. Khati, Director, Rajaji National Park; Mr V. S. Verma, Wildlife Warden, Rajaji National Park; and $\mathrm{Mr} \mathrm{D}$. K. Singh, Wildlife Warden, Kotdwar, provided information on human-elephant conflict. My colleagues Drs G. S. Rawat, S. P. Goyal and A. Rajvanshi were of immense help in the field. Dr Ajith Kumar, Alan Rodgers, Ravi Chellam and Ms Nima Manjrekar commented on the manuscript. $\mathrm{Mr}$ M. P. Aggarwal produced the text.

\section{References}

Dabadghao, P.M. and Shankarnarayan, K.A. 1973. The Grass Cover of India. Indian Council of Agriculture Research, New Delhi.

Daniel, J.C. 1980. Introduction. In The Status of the Asian Elephant in the Indian Sub-continent. (ed. J. C. Daniel), pp. 7-8. IUCN/SSC report, Bombay Natural History Society, Bombay.
Dobias, R.J. 1991. The Ban Sap Tai Project: integrating park conservation and rural development in Thailand. Paper presented at the WII/UNESCO Regional Training Workshop on Wildlife Protected Area Buffer Zone Management, Dehra Dun, India 18-23 February, 19 pp., unpubl.

Harcourt, A.H., Pennington, H. and Weber, A.W. 1986. Public attitudes to wildlife conservation in the Third World. Oryx, 20, 152-154.

Johnsingh, A.J.T. 1991. Rajaji. Sanctuary, 11, 14-25.

Johnsingh, A.J.T. and Panwar, H.S. 1992. Elephant conservation in India - problems and prospects. In Mammal Conservation in Developing Countries (ed. P. Wegge), pp. 36-56. Proceedings of a workshop held at Vth Theriological Congress, Rome, Italy, August 1989.

Johnsingh, A.J.T., Prasad, S.N. and Goyal, S.P. 1990. Conservation of the Chilla-Motichur corridor for elephant movement in Rajaji-Corbett National Parks area, India. Biol. Conserv. 51, 125-138.

Khati, D.V.S. 1990. A Study on the Management of National Park. Second National Management Programmes, Management Development Institute of India, Gurgaon (Haryana), India, 32 pp.

Panwar, H.S. 1987. Project Tiger: the reserves, the tigers and their future. In Tigers of the World: The Biology, Biopolitics, Management and Conservation of an Endangered Species (eds. R. A. Tilson and U. S. Seal), pp. 110-117. Noyes Publications, Park Ridge, New Jersey, USA.

Santiapillai, C. and Jackson, P. 1990. The Asian Elephant: An Action Plan for its Conservation. IUCN, Gland.

Singh, V.B. 1978. The elephant in UP (India) - a resurvey of its status after 10 years. J. Bombay Nat. Hist. Soc. 75, 71-82.

Singh, V.B. 1989. The elephant in UP (India) - the change in status in two decades. Cheetal, 28, 39-43.

A.J.T. Johnsingh and Justus Joshua, Wildlife Institute of India, PB 18, Dehra Dun 248 001, India. 